\title{
POOL BOILING HEAT TRANSFER ON VERTICAL FINS WITH WIRE MESH STRUCTURES
}

\author{
Robert Pastuszko \\ Kielce University of Technology, Chair of Mechanics, \\ al. Tysiąclecia P.P.7, PL-25-314 Kielce, Poland \\ e-mail: tmprp@tu.kielce.pl
}

\begin{abstract}
Experimental investigations into pool boiling heat transfer on finned arrays with internal tunnels limited by copper wire mesh were conducted. The experiments were carried out for water, ethanol and fluorinert FC-72 at atmospheric pressure. The wire net with mesh aperture of 0.3 and $0.5 \mathrm{~mm}$, sintered with the vertical side of the $10 \mathrm{~mm}$ high rectangular fins and horizontal inter-fin surface formed a system of connected tunnels. Tunnel width was 0.6 and $1.0 \mathrm{~mm}$. Substantial enhancement of heat transfer coefficient was observed for the investigated surfaces. In water, ethanol and FC-72 boiling the highest increase in the heat transfer coefficient was obtained for the surface with mesh aperture of 0.5 $\mathrm{mm}$ and tunnel width of $0.6 \mathrm{~mm}$. The ratio of boiling heat transfer coefficients for the investigated fins with mesh covering and smooth fins (10 mm height), at the heat flux $100 \mathrm{~kW} / \mathrm{m}^{2}$, was about 3 for water and ethanol as working fluids.
\end{abstract}

\section{NOMENCLATURE}

a - mesh aperture (opening size), $\mathrm{mm}$

$h \quad-$ height (depth), $\mathrm{mm}$,

N,NTS - narrow tunnel structure,

$p \quad-$ pitch, $\mathrm{mm}$,

$q \quad-$ heat flux, $\mathrm{kW} / \mathrm{m}^{2}$,

$s \quad$ - width of space between fins, $\mathrm{mm}$,

w - width, mm,

\section{Greek symbols}

$\alpha \quad$ - heat transfer coefficient, $\mathrm{kW} / \mathrm{m}^{2} \mathrm{~K}$,

$\delta \quad-$ thickness, $\mathrm{mm}$

$$
\begin{aligned}
& \text { Subscripts } \\
& \text { f - fin, } \\
& \text { p - pore (mesh) } \\
& \text { s - smooth, } \\
& \text { tun - tunnel. }
\end{aligned}
$$

\section{INTRODUCTION}

The paper deals with experimental investigations of boiling heat transfer on structured surfaces in the form of three main fins with parallel narrow tunnels, covered with copper 
mesh. It is a new approach in the area of nucleate pool boiling heat transfer, which employs 3 techniques of heat transfer intensification: surface extension, a narrow tunnel (channel) and a porous structure (mesh).

The structures can be applied for cooling miniature integrated devices, such as microprocessors, as an evaporator in the thermosyphon system substituting forced convection (traditional fan).

Few publications relating to extended surfaces covered with a porous structure can be found in literature. Franco et al. [1] used several layers of wire nets covering the heated surface immersed in boiling R141b. An essential heat transfer coefficient increase was observed for porous structures with $3-7$ layers of nets made of wire with $0.25-0.4$ $\mathrm{mm}$ diameter and mesh aperture of $2 \mathrm{~mm}$. Ma et al. [2] presented experimental investigations of two types of surfaces: (1) with parallel grooves and sintered covering in the form of the wire mesh, (2) with grooves and a brass screen. Water and methanol were used as working fluids. The copper heating surface was a $47 \times 47 \mathrm{~mm}$ horizontally oriented square. The grooves (tunnels) were $0.4-0.6 \mathrm{~mm}$ deep and $0.3-0.5 \mathrm{~mm}$ wide. Experimental results indicated that the heat transfer coefficients from surfaces with mesh aperture of $0.0685 \mathrm{~mm}$ and $0.0913 \mathrm{~mm}$ were much higher than from a surface with aperture of $0.145 \mathrm{~mm}$

Pastuszko [3] presented complex experimental investigations of boiling heat transfer on structured surfaces covered with perforated foil. Experimental data were discussed for two kinds of enhanced surfaces formed by joined horizontal and vertical tunnels: tunnel structures (TS) and narrow tunnel structures (NTS). The experiments were carried out with water, ethanol and R-123 at atmospheric pressure. The TS and NTS surfaces were manufactured out of perforated copper foil of $0.05 \mathrm{~mm}$ thickness, sintered with the minifins, formed on the vertical side of the $5 \mathrm{~mm}$ high rectangular fins and horizontal inter-fin surface. The investigated surfaces showed that for NTS with the narrowest tunnels $(0.6$ $\mathrm{mm})$, pores of the smallest diameter are most advantageous.

Experimental investigations of pool boiling heat transfer on micro-fin arrays covered with porous structure were conducted by Pastuszko [4]. Experimental data were discussed for two kinds of enhanced surfaces: plain micro-fins and micro-fins with the copper wire net (mesh structure) with micro-fins of 0.5 and $1 \mathrm{~mm}$ height. The wire mesh with aperture of $0.32,0.4$ and $0.5 \mathrm{~mm}$, sintered with the fin tips, formed a system of connected perpendicular horizontal tunnels. Tunnel width was $0.6-1.0-1.5 \mathrm{~mm}$ and its depth was 0.5 or $1.0 \mathrm{~mm}$. Structures with micro-fins of $1 \mathrm{~mm}$ height showed the best boiling heat transfer performance for water at all used heat fluxes and at the medium and highest heat fluxes for FC-72. For FC-72 at high heat fluxes (above $30 \mathrm{~kW} / \mathrm{m}^{2}$ for shorter microfins and $50 \mathrm{~kW} / \mathrm{m}^{2}$ for higher micro-fins) surfaces with plain micro-fins showed the highest heat transfer coefficients.

The objective of this article is to determine the most advantageous geometry of new enhanced structures with narrow tunnels with respect to boiling heat transfer coefficient intensification, taking into account heat fluxes in the range of $10-300 \mathrm{~kW} / \mathrm{m}^{2}$.

\section{EXPERIMENTAL SET-UP}

Figure 1 presents the diagram of the measurement stand for the determination of boiling curves is presented in Fig.1. Its main module is constructed in a similar way to the modules described in $[3,4]$. 


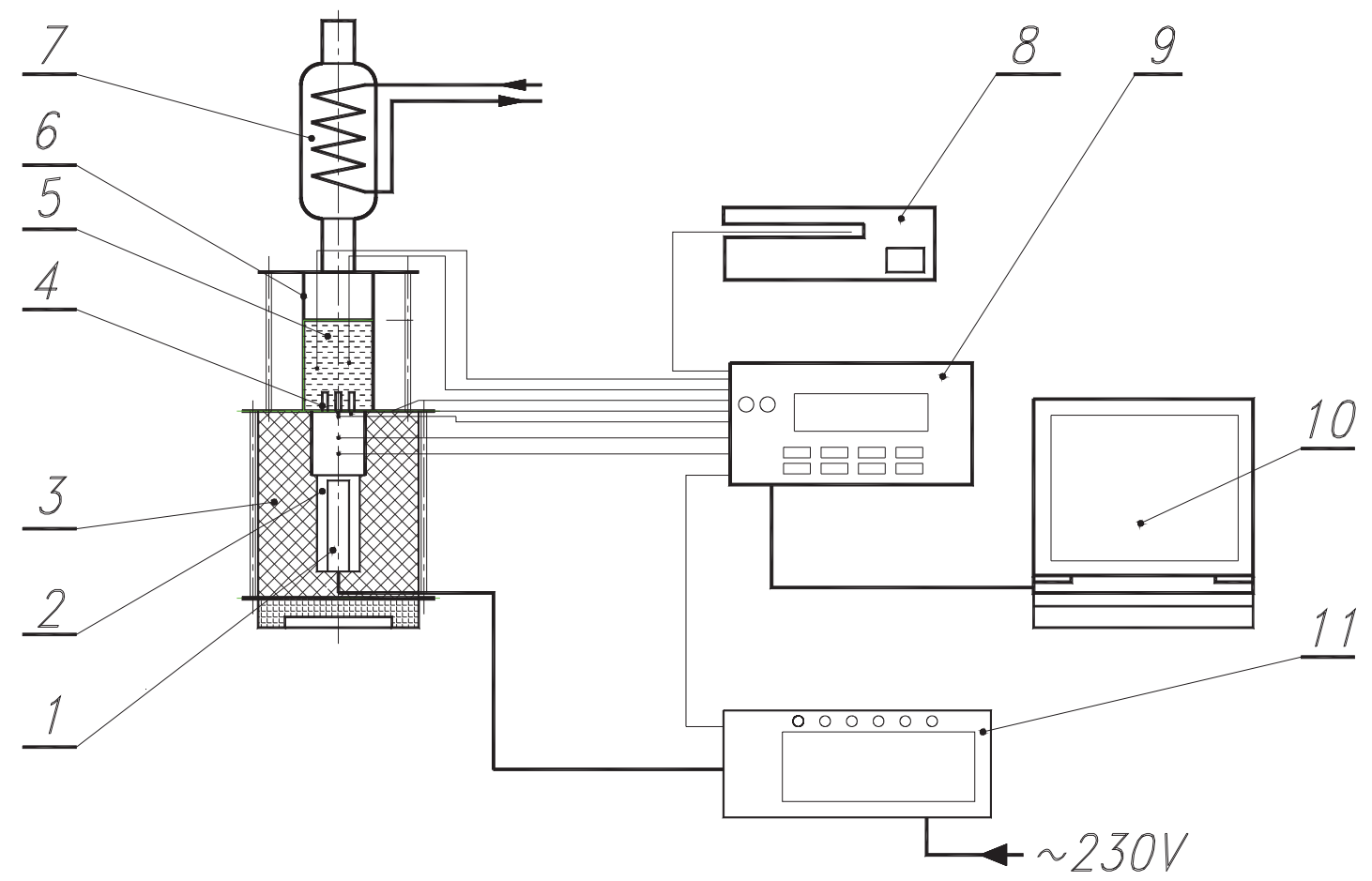

Fig. 1. Schematic diagram of the test system: 1 - cartridge heater; 2 - copper bar; 3 - insulation; 4 - investigated structure; 5 - boiling liquid; 6 - glass vessel; 7 - condenser; 8 - dry-well calibrator; 9 - data logger; 10 - PC; 11 power regulator.

The heat flux was determined on the basis of the temperature gradient in the upper part of the heating cylinder, with the assumption of one-dimensional heat conduction.

Temperature superheat, heat flux and boiling heat transfer coefficient were related to the level of main fin base.

The estimated uncertainties were as follows:

- low heat flux $\left(2 \mathrm{~kW} / \mathrm{m}^{2}\right)$ : heat flux $\pm 35 \%$, heat transfer coefficient $\pm 40 \%$,

- high heat flux $\left(350 \mathrm{~kW} / \mathrm{m}^{2}\right)$ : heat flux $\pm 0.2 \%$, heat transfer coefficient $\pm 1.1 \%$.

Because the differences between the values $\alpha$ at increasing and decreasing heat flux did not exceed the margin of measurement error, Figs $4-6$ present boiling curves only for the increasing $q$.

\section{SAMPLES}

The enhanced structures which are the focus of the present study are shown in Figs 2 and 3.

Samples with the tunnel structure formed a square of $27 \mathrm{~mm}$ long side. They had three main fins with additional surface modification. Tunnels were formed by cutting grooves in main fins (vertical tunnels) and in the surface between main fins (horizontal tunnels). The tunnels are closed with sintered copper wire mesh. The constant parameters of the samples were as follows (Figs 2 and 3): main fin number: 3 , width of space between fins $(s): 5 \mathrm{~mm}$, fin thickness $\left(\delta_{\mathrm{f}}\right): 5 \mathrm{~mm}$. 

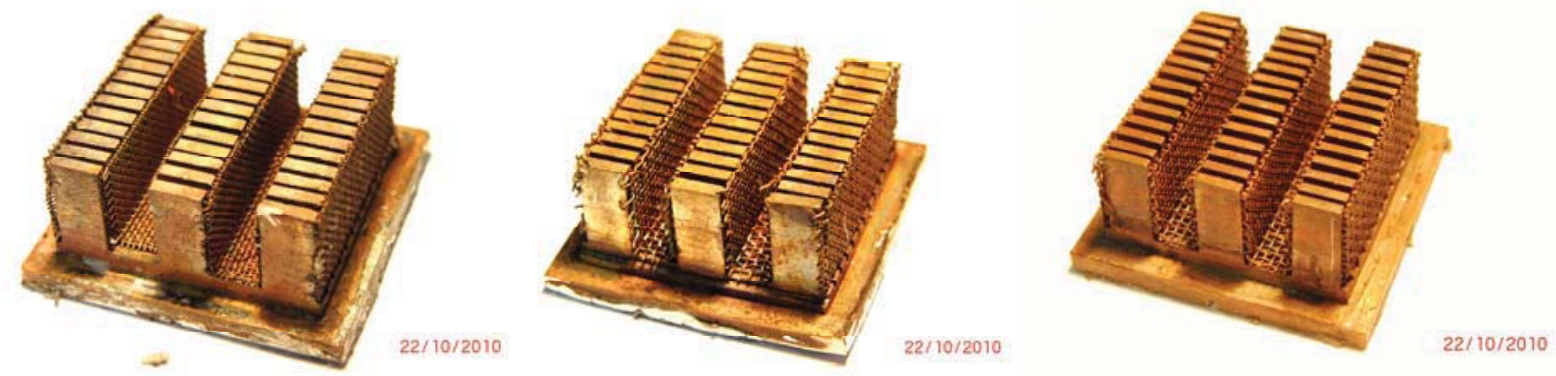

Figure 2. Photograph of NTS samples with wire mesh $(\mathrm{N}-10-0.6-03, \mathrm{~N}-10-0.6-$ 0.5, N-10-1.0-0.5).
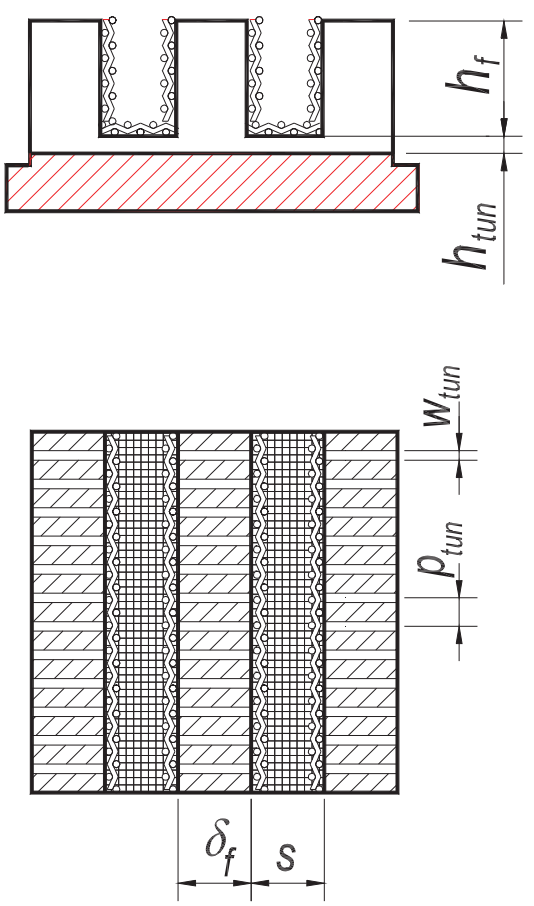

Figure 3. Vertical and horizontal cross-section of fin arrays.

The parameters of the structures discussed above with the notations as in Fig. 3 are shown in Table 1.

Table 1. Sample codes and specifications.

\begin{tabular}{|llllll|}
\hline Sample code & $\begin{array}{l}\text { mesh } \\
\text { aperture } \\
a, \mathrm{~mm}\end{array}$ & $\begin{array}{l}\text { mesh } \\
\text { pitch, } \\
p_{\mathrm{p}}, \mathrm{mm}\end{array}$ & $\begin{array}{l}\text { tunnel } \\
\text { width } \\
w_{\text {tun, }} \mathrm{mm}\end{array}$ & $\begin{array}{l}\text { tunnel } \\
\text { pitch } \\
p_{\text {tun }}, \mathrm{mm}\end{array}$ & $\begin{array}{l}\text { horizontal } \\
\text { tunnel depth, } \\
h_{\text {tun, }} \mathrm{mm}\end{array}$ \\
\hline $\mathrm{N}-10-0.6-0.3$ & 0.32 & 0.52 & 0.6 & 2.00 & 1.0 \\
\hline $\mathrm{N}-10-0.6-0.5$ & 0.5 & 0.82 & 0.6 & 2.00 & 1.0 \\
\hline $\mathrm{N}-10-1.0-0.5$ & 0.5 & 0.82 & 1.0 & 2.00 & 1.0 \\
\hline $\mathrm{N}-10-00$ & - & - & - & - & - \\
\hline
\end{tabular}


Designation "00" at the end of the sample's code refers to surface with main fins without any modification ("smooth fin"). Heat transfer coefficients for water and ethanol were compared with coefficients obtained for surfaces with smooth fins and the following dimensions: $h_{\mathrm{f}}=10 \mathrm{~mm}, \delta=5 \mathrm{~mm}, s=5 \mathrm{~mm}$.

\section{Results}

\subsection{WATER}

The effect of the pore diameter and tunnel width for boiling water is shown in Fig. 4. For the all investigated surfaces with wire mesh with small heat fluxes $\left(q<120 \mathrm{~kW} / \mathrm{m}^{2}\right)$ there were obtained similar results, considering measurement errors.

For $q=120-300 \mathrm{~kW} / \mathrm{m}^{2}$, the increase in the heat transfer coefficient for all NTS - when compared with smooth fins $\left(\alpha / \alpha_{\mathrm{sf}}\right)$ was in the range of 2.5 to 3.5 (N10-0.6-0.5). At $q=300 \mathrm{~kW} / \mathrm{m}^{2}$, the heat transfer coefficient for the surface with tunnel width of 0.6 and mesh aperture of $0.5 \mathrm{~mm}$ was about $20 \%$ bigger than the coefficients for two other NTS surfaces.

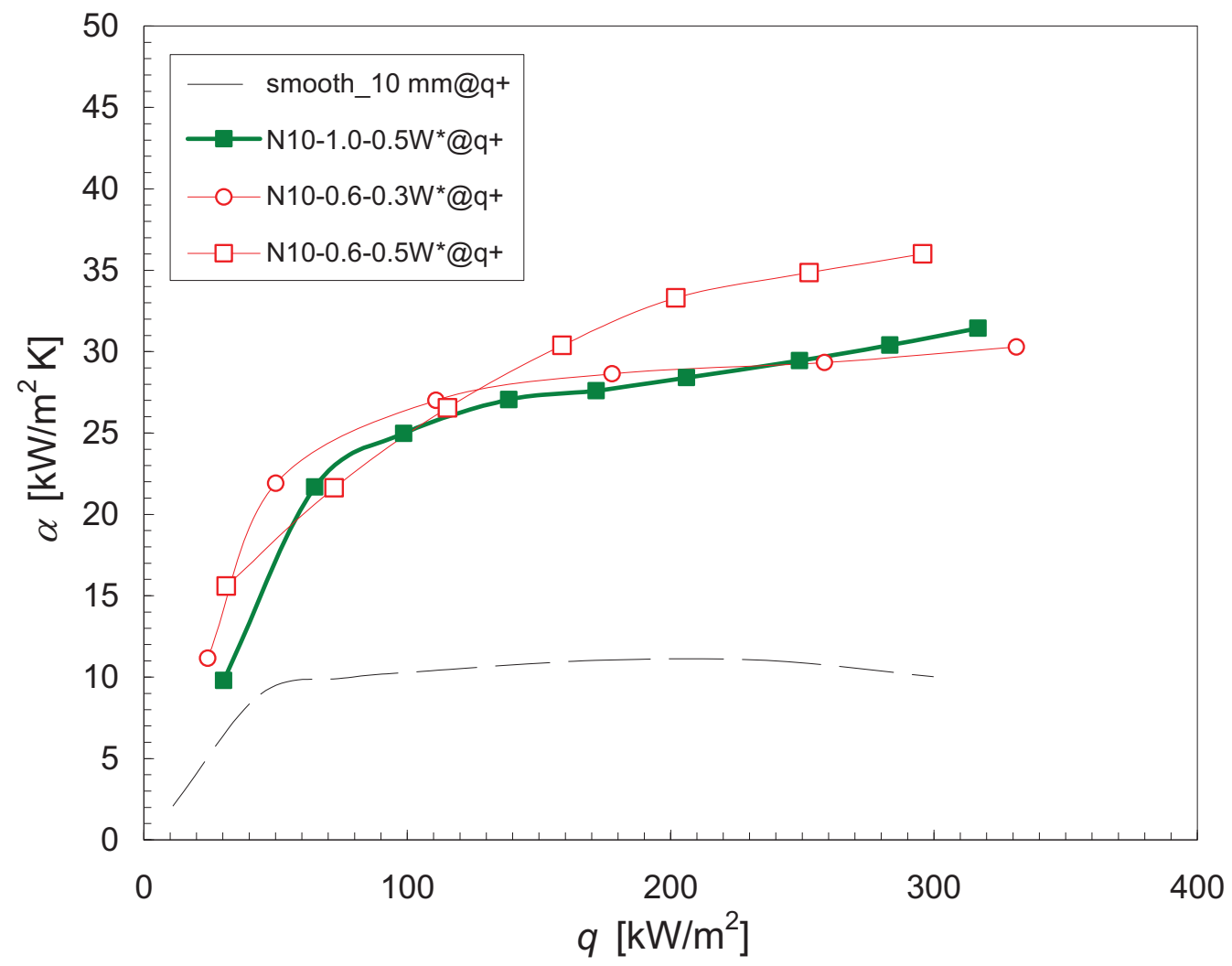

Fig.4. Boiling heat transfer data for water at $99.3-99.9^{\circ} \mathrm{C}$ with the increasing heat flux. 


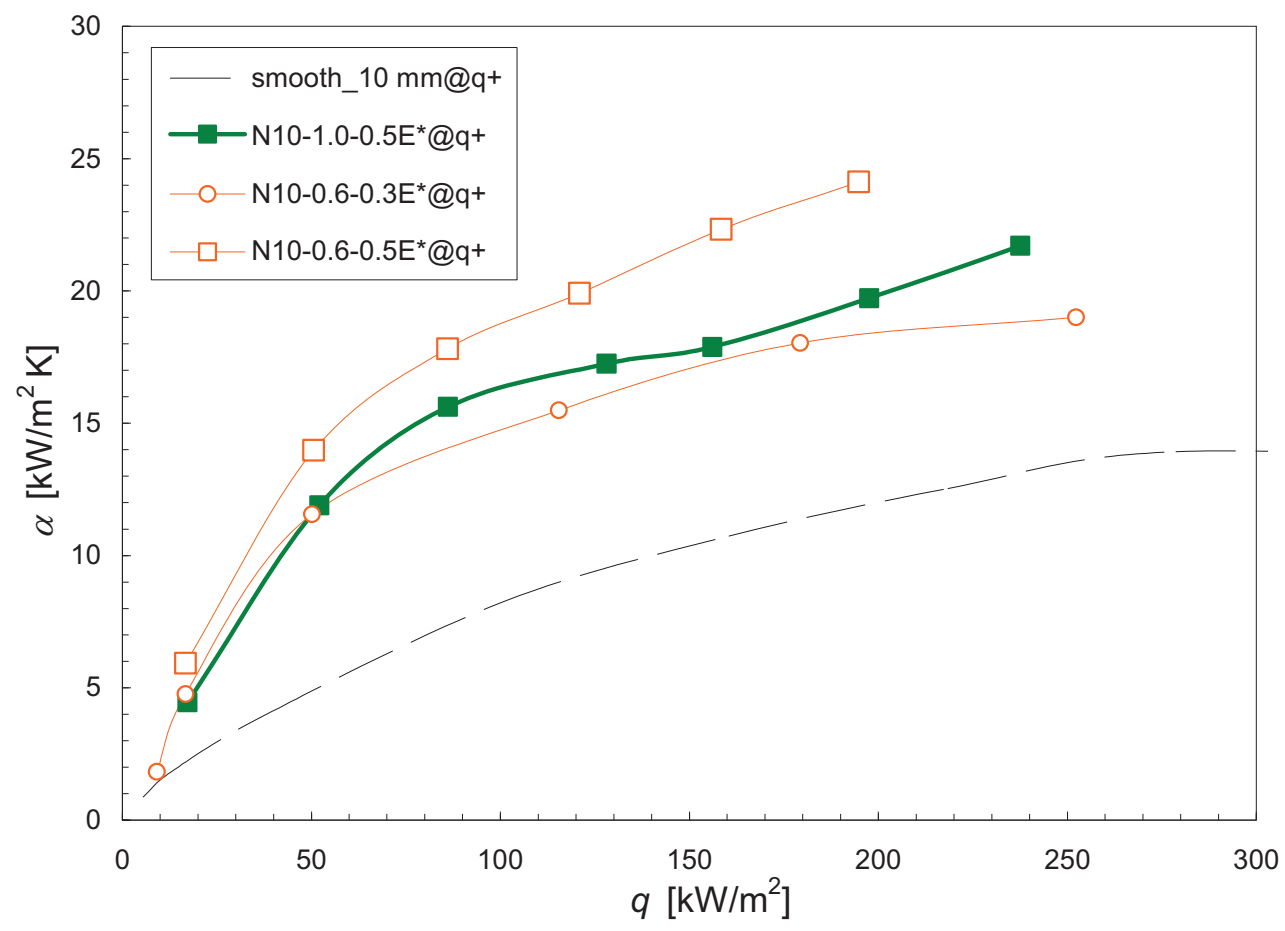

Fig.5. Boiling heat transfer data for ethanol at $77.3-78.7^{\circ} \mathrm{C}$ with the increasing heat flux.

\subsection{Ethanol}

For ethanol (Fig. 5), as in the case of water, surfaces with narrowest tunnel $(0.6 \mathrm{~mm})$ and large mesh aperture $(0.5 \mathrm{~mm})$ are efficient in the whole range of the used heat fluxes $\left(20 \mathrm{~kW} / \mathrm{m}^{2}<q<200 \mathrm{~kW} / \mathrm{m}^{2}\right)$. The application of this surface resulted in obtaining 2.5 times higher heat transfer coefficient in comparison with the smooth-fin surface $\left(\alpha / \alpha_{\mathrm{sf}} \approx 2.5\right)$. In relation to the other NTS, the increase in the heat transfer coefficient was about $20 \%$ in the heat flux range as cited above, and below $50 \mathrm{~kW} / \mathrm{m}^{2}$ the differences were within the measurement error margin.

\subsection{FC-72}

For Fluorinert (Fig. 6), the surface with $0.6 \mathrm{~mm}$ wide tunnel and mesh aperture of 0.5 $\mathrm{mm}$ also performed best in promoting heat transfer (nearly $14 \mathrm{~kW} / \mathrm{m}^{2} \mathrm{~K}$ at $q=100-150$ $\left.\mathrm{kW} / \mathrm{m}^{2}\right)$. At low heat fluxes $\left(q<40 \mathrm{~kW} / \mathrm{m}^{2}\right)$ and as in the case of water and ethanol, the boiling heat transfer coefficients for all investigated surfaces had similar values (in the measurement error margin). At heat fluxes above $50 \mathrm{~kW} / \mathrm{m}^{2}$ mesh openings hinder vapor removal, resulting in the flooding of tunnels and lower increases in $\alpha$.

The diagram shows the comparison with surface NL-1.0-1.0, the structure which is a system of $1 \mathrm{~mm}$-high micro-fins with interfin spaces of 1 and $2 \mathrm{~mm}$ [4], in two perpendicular directions respectively. One can observe that this surface makes it possible to obtain heat transfer coefficient values close to $\alpha$ for surfaces $\mathrm{N} 10-1.0-0.5$ and N10$0.6-0.3$, i.e. $8-9 \mathrm{~kW} / \mathrm{m}^{2} \mathrm{~K}$ at $q>100 \mathrm{~kW} / \mathrm{m}^{2}$. 


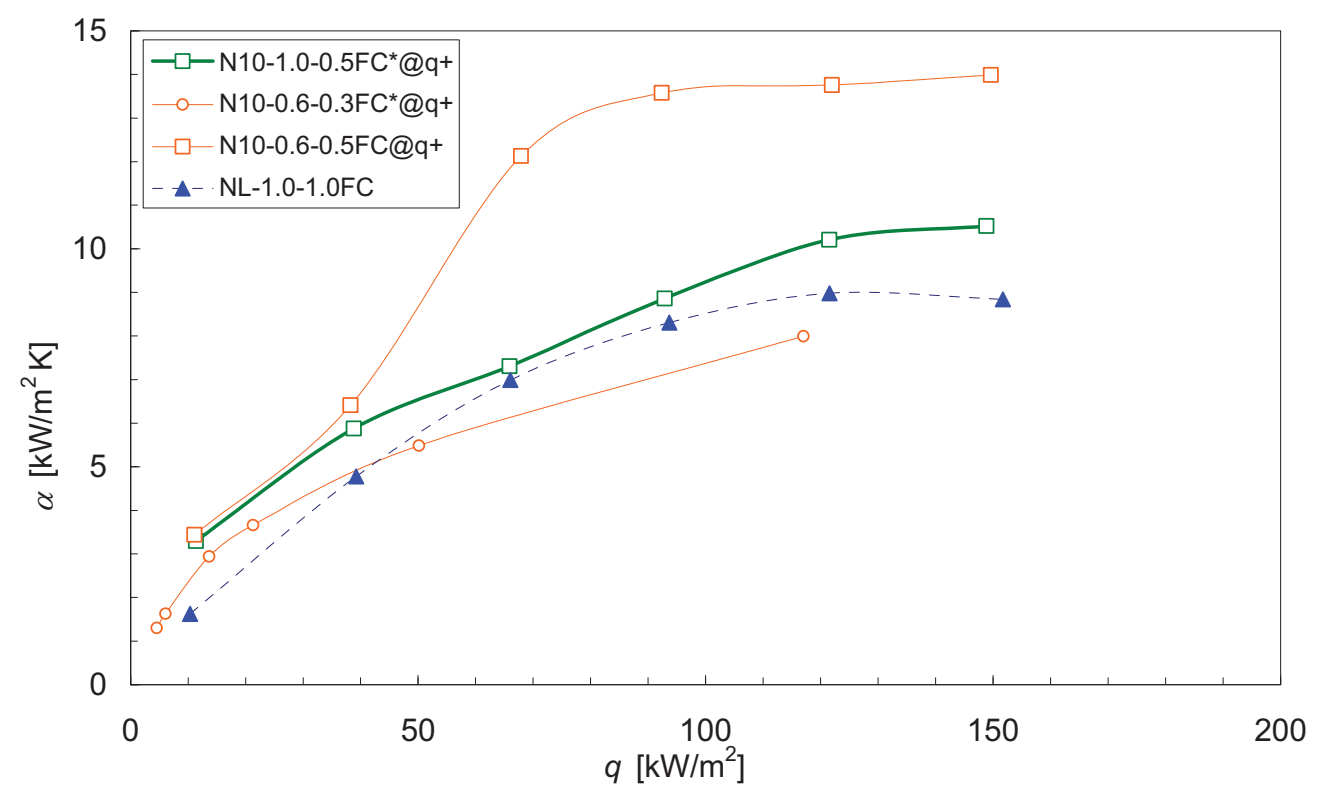

\section{Fig.6. Boiling heat transfer data for FC-72 at $56-56.6{ }^{\circ} \mathrm{C}$ with increasing $q$.}

\section{Conclusions}

- The best results at boiling water and ethanol at whole range of heat fluxes (30 $300 \mathrm{~kW} / \mathrm{m}^{2}$ for water, $20-200 \mathrm{~kW} / \mathrm{m}^{2}$ for ethanol, $10-150 \mathrm{~kW} / \mathrm{m}^{2}$ for FC-72) were obtained for tunnels of $0.6 \mathrm{~mm}$ width with copper wire mesh aperture of 0.5 $\mathrm{mm}$. Heat transfer coefficients for water and ethanol were about 3 times higher than those obtained with smooth fins.

- One can assume that the mesh aperture similar to the tunnel width ensures the balance between the liquid inflow into the tunnels and vapor outflow, or that both tunnel flooding and tunnel drying are minimized.

- The comparison with a square pin fin array shows that the obtained heat transfer coefficient values are in good agreement.

\section{ACKNOWLEDGMENTS}

This paper was partly supported by the Polish Ministry of Science and Higher Education, Grant No. N N512 317338.

\section{REFERENCES}

[1] Franco A., Latrofa E.M., Yagov V.V.: Heat transfer enhancement in pool boiling of a refrigerant fluid with wire nets structures, Experimental Thermal and Fluid Science, 30 (2006), 263-275.

[2] Ma T., Liu X., Wu J., Li H.: Effects of Geometrical Shapes and Parameters of Reentrant Grooves on Nucleate Pool Boiling Heat Transfer from Porous Surfaces, Proc. 8th Int. Heat Transfer Conf., San Francisco, USA, 1986, 2013-2018.

[3] Pastuszko R.: Boiling heat transfer enhancement in subsurface horizontal and vertical tunnels, Experimental Thermal and Fluid Science 32 (2008), 1564 1577.

[4] Pastuszko R.: Pool boiling on micro-fin array with wire mesh structures, International Journal of Thermal Sciences 49 (2010), 2289-2298. 